\title{
Media Edukasi Tanda Bahaya Kehamilan Berbasis Android Untuk Meningkatkan Pengetahuan Ibu Hamil
}

\author{
Education Media Of Android-Based Hazard Pregnancy To Increase \\ Pregnancy Mother's Knowledge
}

\author{
Wahyu Nindi Sayekti ${ }^{1}$, Syafruddin Syarif ${ }^{2}$, Mardiana Ahmad ${ }^{3}$, Etty Nurkhayati ${ }^{4}$, Siti Suciati $^{5}$ \\ ${ }^{1,3}$ Prodi S2 Kebidanan Sekolah Pascasarjana Universitas Hasanuddin Makassar \\ ${ }^{2}$ Fakultas Tehnik Universitas Hasanuddin Makassar \\ ${ }^{4}$ Prodi Pendidikan S1 bidan Universitas Faletehan \\ ${ }^{5}$ Prodi D3 Kebidanan Universitas Tulungagung \\ 1Email: wahyunindisayekti@ pasca.unhas.ac.id
}

\begin{abstract}
ABSTRAK
Edukasi selama kunjungan Antenatal Care (ANC) tentang tanda bahaya kehamilan penting dilakukan, karena dapat meningkatkan kesadaran ibu hamil terhadap tanda bahaya kehamilan sehingga secara cepat dan tepat mencari perawatan kesehatan yang akan mengurangi terjadinya komplikasi. Penelitian ini bertujuan menghasilkan produk media edukasi tanda bahaya kehamilan berbasis android. Penelitian ini menggunakan desain penelitian metode Research and Development (R \& D) yang dikembangkan oleh Borg and Gall. Sampel pada penelitian ini adalah $30 \mathrm{ibu}$ hamil dengan menggunakan teknik sampling incidental di Puskesmas Antang Perumnas Makassar. uji statistik yang digunakan adalah Wilcoxon Signed Rank Test. Penilaian aplikasi dilakukan dengan menggunakan kuisioner Technology Acceptance Model (TAM) untuk menilai tingkat kegunaan aplikasi. Hasil penelitian menunjukkan bahwa aplikasi diterima sangat baik oleh ibu hamil sehingga pengembangan media edukasi kesehatan tentang tanda bahaya kehamilan berbasis android dapat meningkatkan pengetahuan ibu hamil tentang tanda bahaya kehamilan.
\end{abstract}

Kata kunci : Media Edukasi Tanda Bahaya Kehamilan, Android, Pengetahuan Ibu Hamil.

\section{ABSTRACT}

Education during Antenatal Care (ANC) visits about pregnancy danger signs is important, because it can increase the awareness of pregnant women about pregnancy danger signs so that they quickly and accurately seek health care that will reduce the occurrence of complications. This study aims to produce education products based on android pregnancy danger signals. This study used a Research and Development $(R \& D)$ research design method developed by Borg and Gall. The sample in this study was 30 pregnant women using incidental sampling techniques at the Antang Public Health Center, Perumnas Makassar. The statistical test used Wilcoxon Signed Rank Test. Application evaluation was done by using the Technology Acceptance Model (TAM) questionnaire to assess the level of application usability. The results showed that the application was received very well by pregnant women so that the development of health education media about Android-based pregnancy danger signs could increase the knowledge of pregnant women about pregnancy danger signs.

Keywords: Education Media Pregnancy Signs, Android, Knowledge of Pregnant Women. 


\section{PENDAHULUAN}

Edukasi kesehatan merupakan bagian dari pendidikan kesehatan yang dapat diartikan sebagai pemberi informasi, instruksi, dan peningkatan pemahaman terkait kesehatan (Notoatmodjo S, 2014). Edukasi kesehatan dapat diberikan secara langsung atau melalui media tertentu, media edukasi kesehatan membantu mempermudah dalam penyampaian pesan kesehatan (Nursalam \& Efendi, 2014). Edukasi selama kunjungan Antenatal Care (ANC) tentang tanda bahaya kehamilan penting dilakukan, karena dapat meningkatkan kesadaran ibu hamil terhadap tanda bahaya kehamilan sehingga secara cepat dan tepat mencari perawatan kesehatan yang akan mengurangi terjadinya komplikasi yang mengakibatkan meningkatnya angka kesakitan dan kematian ibu (Assaf, 2018; Williams et al., 2013).

Ibu hamil berisiko menghadapi komplikasi yang timbul selama kehamilan, dan sekitar 15\% dari semua ibu hamil mengalami komplikasi kebidanan (WHO, UNICEF, \& UNFA, 2015). Bukti menyatakan bahwa setiap hari terdapat sekitar 14.000 kematian ibu sebagai akibat dari komplikasi kehamilan dan persalinan (Hibstu \&
Siyoum, 2017). Pengetahuan ibu tentang tanda bahaya kehamilan secara positif mempengaruhi keputusan mereka mengenai kapan mencari perawatan medis (Mwilike et al, 2018).

Berdasarkan hasil penelitian yang dilakukan oleh Vallely et al tahun 2019, mendapati sebanyak 39\% ibu hamil mengetahui satu tanda bahaya kehamilan, sebanyak 39\% mengetahui dua tanda bahaya, dan sebanyak $22 \%$ mengetahui tiga tanda bahaya. Tanda bahaya kehamilan yang wajib diketahui yaitu: perdarahan pada kehamilan muda dan lanjut, penglihatan kabur, bengkak pada wajah atau ekstremitas tangan dan kaki, gerakan janin berkurang, nyeri perut hebat, ketuban pecah dini, kejang, dan demam tinggi (Haleema et al, 2019; Hartini, 2018; Lee \& Saha, 2013).

Edukasi tanda bahaya kehamilan selama masa kehamilan secara umum diberikan dengan media Buku Kesehatan Ibu dan Anak (KIA), dan poster. Perkembangan teknologi dan kepemilikan handphone sudah semakin meningkat mendorong penggunaan media edukasi berbasis android dalam pelayanan kesehatan. Penelitian yang dilakukan Elliana \& Kurniawati tahun 2015 menunjukkan hasil adanya perbedaan pengetahuan responden 
antara sebelum dan sesudah pemberian SMS gateway tentang tanda bahaya kehamilan dengan nilai asymp sign $0,038(\mathrm{p}<0,05)$.

Hasil studi pendahuluan didapati bahwa pada Puskesmas Perumnas Antang memberikan edukasi kepada ibu hamill tentang tanda bahaya kehamilan dengan menggunakan media seperti Buku KIA, leaflet, dan poster. Hasil wawancara singkat dengan $5 \mathrm{ibu}$ hamil mendapati bahwa mereka hanya mengetahui 7 tanda bahaya kehamilan dari 12 tanda bahaya yang harus mereka ketahui. Pengetahuan ibu hamil tentang tanda bahaya kehamilan berdasarkan hasil studi awal dan beberapa penelitian masih rendah, hal tersebut akan berdampak pada tingkat kesehatan maternal dan perinatal.

Edukasi kesehatan yang didukung dengan teknologi memberikan keleluasaan mendapatkan informasi dengan lengkap, aplikasi berbasis android bisa memberikan informasi lebih cepat, mudah dan bisa digunakan dimana saja dan dapat diakses kapan saja. Sehingga aplikasi berbasis android menjadi solusi dalam memberikan informasi dalam upaya meningkatkan pengetahuan ibu hamil tentang tanda bahaya kehamilan.
Tujuan dalam penelitian ini adalah untuk menghasilkan produk media edukasi tanda bahaya kehamilan berbasis android untuk meningkatkan pengetahuan ibu hamil.

\section{METODE PENELITIAN}

Penelitian ini adalah menggunakan desain penelitian dengan metode Research and Development ( $\mathrm{R}$ \& D) yang dikembangkan oleh Borg and Gall, merupakan suatu proses untuk mengembangkan dan menvalidasi produk pendidikan (H. R. Borg and M. D. Gall, 1983). Tahapan penelitian ini terdiri dari: 1) analisis kebutuhan media edukasi khususnya tanda bahaya kehamilan, 2) desain pengembangan media edukasi, 3) pengembangan media edukasi, 4) validasi ahli, 5) uji coba satu-satu, 6) uji coba kelompok kecil, 7) uji coba kelompok besar, dan 8) produk akhir media edukasi. Penelitian ini terdiri dari kelompok intervensi yang mendapatkan edukasi tanda bahaya kehamilan berbasis android.

Sampel dalam penelitian ini dipilih secara teknik sampling incidental dan dilaksankan pada bulan 21 Januari - 3 Februari 2020. Instrument yang digunakan dalam penelitian ini yaitu aplikasi media 
edukasi tanda bahaya kehamilan berbasis android, kuisioner Technology Acceptance Model (TAM) untuk menilai tingkat kegunaan aplikasi, kuisioner validasi media dan materi, dan kuisioner pengetahuan tanda bahaya kehamilan. Teknik analisis data univariat dan bivariat (Wilcoxon Signed Rank Test) untuk mengetahui perbedaan pengetahuan ibu hamil tentang tanda bahaya kehamilan sebelum dan sesudah di berikan aplikasi media edukasi tanda bahaya kehamilan berbasis android. Wilcoxon Signed Rank Test adalah uji statistik non parametrik pada data dua kelompok berpasangan tidak berdistribusi normal

\section{HASIL DAN PEMBAHASAN}

A. Umur

Tabel 1. Frekuensi Karakteristik Berdasarkan Umur Ibu Hamil di Puskesmas Antang Perumnas.

\begin{tabular}{ccc}
\hline Umur (Tahun) & Frekuensi & $\mathbf{\%}$ \\
\hline$<20$ Tahun & 5 & 16,7 \\
20-35 Tahun & 19 & 63,3 \\
$>$ 35 Tahun & 6 & 20 \\
Jumlah & $\mathbf{3 0}$ & $\mathbf{1 0 0}$ \\
\hline
\end{tabular}

Berdasarkan tabel 1 di atas menunjukkan bahwa mayoritas ibu hamil di Puskesmas Antang Perumnas berumur 20-35 tahun sebanyak 19 orang $(63,3 \%)$.
B. Pendidikan

Tabel 2. Frekuensi Karakteristik Berdasarkan Tingkat Pendidikan Ibu Hamil di Puskesmas Antang Perumnas.

\begin{tabular}{lcc}
\hline Pendidikan & Frekuensi & \% \\
\hline SMP & 4 & 13,4 \\
SMA & 16 & 53,3 \\
D3/SI & 10 & 33,3 \\
Jumlah & $\mathbf{3 0}$ & $\mathbf{1 0 0}$ \\
\hline
\end{tabular}

Berdasarkan tabel 2 di atas menunjukkan bahwa mayoritas ibu hamil di Puskesmas Antang Perumnas dengan tingkat pendidikan SMA sebanyak 16 orang $(53,3 \%)$.

C. Riwayat Kehamilan

Tabel 3. Frekuensi Karakteristik Berdasarkan Riwayat Kehamilan pada Ibu Hamil di Puskesmas Antang Perumnas

\begin{tabular}{lcc}
\hline Riwayat Hamil & Frekuensi & \% \\
\hline Belum Pernah & 10 & 33,3 \\
1 kali & 12 & 40 \\
$>$ 1 kali & 8 & 26,7 \\
$\quad$ Jumlah & $\mathbf{3 0}$ & $\mathbf{1 0 0}$ \\
\hline
\end{tabular}

Berdasarkan tabel 3 di atas menunjukkan bahwa mayoritas ibu hamil dengan riwayat kehamilan 1 kali sebanyak 12 orang (40\%). 
D. Tahapan Pengembangan

1. Analisis kebutuhan dengan tahapan studi lapangan tentang tanda bahaya kehamilan yang sudah ada di Puskesmas Antang Perumnas menggunakan Buku KIA, leaflet dan poster, pada kajian pustaka didapati dari penelitian yang sudah ada hanya menggunakan media Buku KIA.

2. Desain pengembangan media edukasi kesehatan tentang tanda bahaya kehamilan berbasis android. Pada tahap ini peneliti melakukan perancangan desain dan fitur yang akan di tampilkan pada media edukasi tanda bahaya kehamilan berbasis android dengan bantuan orang yang ahli di bidang teknologi informasi.

3. Pengembangan media edukasi kesehatan tentang tanda bahaya kehamilan berbasis android. Pada tahap ini peneliti melakukan pengembangan media edukasi tanda bahaya kehamilan yang sudah ada seperti di Buku KIA, dengan perubahan menggunakan media android dan penambahan penjelasan secara lebih lengkap pada setiap tanda bahaya kehamilan, penambahan fitur chat online dan fitur deteksi dini terhadap tanda bahaya kehamilan yang didapat dari hasil menjawab pertanyan-pertanyaan yang telah tersedia.

4. Validasi ahli. Pada tahap ini peneliti melakukan validasi terdiri atas dua ahli, yaitu Ahli Media dan Ahli Materi pada aplikasi media edukasi tanda bahaya kehamilan berbasis android. Hasil perhitungan persentase kelayakan aplikasi maka diperoleh persentase kelayakan sebesar $87,5 \%$ sehingga dapat disumpulkan bahwa aplikasi media edukasi tanda bahaya kehamilan berbasis android dikategorikan sangat layak.

5. Melakukan uji coba satu-satu dengan semua Bidan yang bertugas di ruangan KIA Puskesmas Perumnas Antang sebanyak 4 orang (3 bidan PNS dan 1 Bidan honorer) untuk mendapat masukan atas penjelasan materi, fitur dan desain pada aplikasi tersebut dengan mengisi kuisioner Technology Acceptance Model (TAM).

6. Melakukan uji coba kelompok kecil dengan ibu hamil sebanyak 10 orang, aplikasi diberikan dan dilakukan 
pengambilan kuisioner Technology

Acceptance Model (TAM).

7. Melakukan uji coba kelompok besar dengan ibu hamil 30 orang kelompok intervensi diberikan aplikasi kemudian dilakukan pengambilan kuisioner Technology Acceptance Model (TAM) dan kuisioner pengetahuan tanda bahaya kehamilan.

E. Penilaian Aplikasi berdasarkan Perilaku Pengguna

Tabel 4. Pengujian deskriptif perceived ease to use dalam penggunaan aplikasi oleh ibu hamil di Puskesmas Antang Perumnas. Descriptive Statistic

\begin{tabular}{ccccc} 
& N & Min & Max & Mean \\
\hline PE1 & 30 & 4 & 5 & 4,40 \\
PE2 & 30 & 3 & 5 & 3,77 \\
PE3 & 30 & 3 & 4 & 3,97 \\
PE4 & 30 & 3 & 5 & 4,13 \\
Average & & & & 4,06
\end{tabular}

Berdasarkan tabel 4 di atas

menunjukkan bahwa total nilai ratarata Mean pada variabel perceived ease to use dari jumlah responden 30 dengan 4 pertanyaan yaitu sebesar 4,06 yang artinya kemudahan pengguna terhadap penggunaan aplikasi tanda bahaya kehamilan sangat baik karena nilai skor rata-rata 4,06 berada di atas nilai tengah antara nilai minimum dan maksimum.
Tabel 5. Pengujian deskriptif perceived usefulness dalam penggunaan aplikasi oleh ibu hamil di Puskesmas Antang Perumnas.

Descriptive Statistic

\begin{tabular}{ccccc} 
& N & Min & Max & Mean \\
\hline PU1 & 30 & 4 & 5 & 4,37 \\
PU2 & 30 & 3 & 5 & 4,14 \\
PU3 & 30 & 3 & 5 & 3,77 \\
Average & & & & 4,1 \\
\hline
\end{tabular}

Berdasarkan tabel 5 di atas menunjukkan bahwa total nilai ratarata Mean pada variabel perceived usefulness dari jumlah responden 30 dengan 3 pertanyaan yaitu sebesar 4,1 yang artinya pandangan pengguna terhadap penggunaan aplikasi tanda bahaya kehamilan sangat baik karena nilai skor rata-rata 4,1 berada di atas nilai tengah antara nilai minimum dan maksimum.

Tabel 6. Pengujian deskriptif Trust dalam penggunaan aplikasi oleh ibu hamil di Puskesmas Antang Perumnas.

\begin{tabular}{ccccc}
\hline \multicolumn{5}{c}{ Descriptive Statistic } \\
& $\mathrm{N}$ & Min & Max & Mean \\
\hline T1 & 30 & 3 & 4 & 3,67 \\
T2 & 30 & 4 & 5 & 4,17 \\
T3 & 30 & 4 & 5 & 4,30 \\
Average & & & & 4,04 \\
\hline
\end{tabular}

Berdasarkan tabel 6 di atas menunjukkan bahwa total nilai rata-rata Mean pada variabel Trust dari jumlah 
responden 30 dengan 3 pertanyaan yaitu sebesar 4,04 yang artinya pandangan kepercayaan pengguna terhadap penggunaan aplikasi tanda bahaya kehamilan sangat baik karena nilai skor rata-rata 4,04 berada di atas nilai tengah antara nilai minimum dan maksimum.

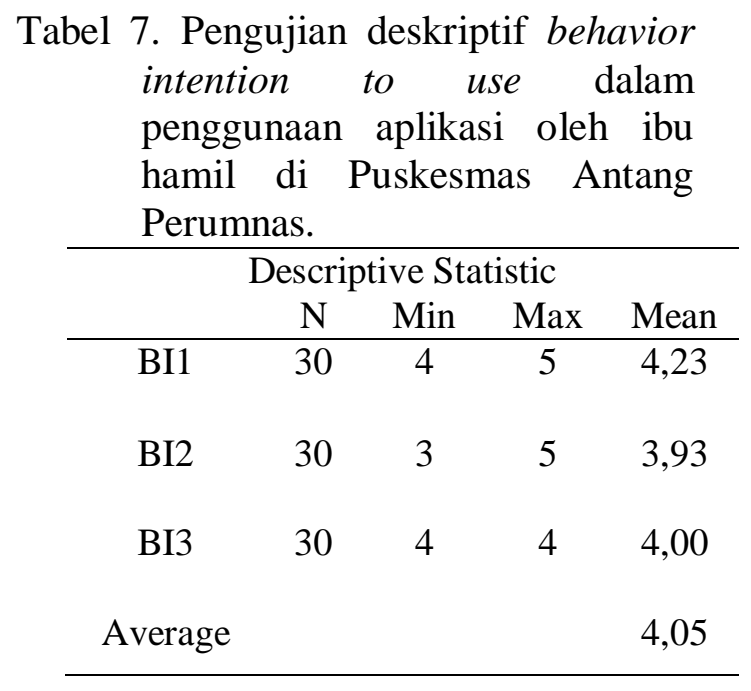

Berdasarkan tabel 7 di atas menunjukkan bahwa total nilai ratarata Mean pada variabel behavior intention to use dari jumlah responden 30 dengan 3 pertanyaan yaitu sebesar 4,05 yang artinya tingkat minat pengguna terhadap penggunaan aplikasi tanda bahaya kehamilan sangat baik karena nilai skor rata-rata 4,05 berada di atas nilai tengah antara nilai minimum dan maksimum.

Tabel 8. Pengujian deskriptif attitude toward using dalam penggunaan aplikasi oleh ibu hamil di Puskesmas Antang Perumnas.

\begin{tabular}{ccccc}
\hline \multicolumn{5}{c}{ Descriptive Statistic } \\
& N & Min & Max & Mean \\
\hline AT1 & 30 & 3 & 5 & 4,27 \\
AT2 & 30 & 3 & 5 & 3,97 \\
Average & & & & 4,11 \\
\hline
\end{tabular}

Berdasarkan tabel 8 di atas menunjukkan bahwa total nilai ratarata Mean pada variabel attitude toward using dari jumlah responden 30 dengan 2 pertanyaan yaitu sebesar 4,11 yang artinya sikap pengguna terhadap penggunaan aplikasi tanda bahaya kehamilan sangat baik karena nilai skor rata-rata 4,11 berada di atas nilai tengah antara nilai minimum dan maksimum.

\section{F. Analisis Bivariat}

Tabel 10. Frekuensi Berdasarkan Analisis Pengetahuan Ibu Hamil.

\begin{tabular}{cccccc}
\hline & & $\mathrm{N}$ & Mean Rank & Sum of Ranks & p-value \\
\hline \multirow{3}{*}{ Posttest - Pretest } & Negative Ranks & $0^{\mathrm{a}}$ & 0.00 & 0.00 & 0,000 \\
& Psitive Ranks & $30^{\mathrm{b}}$ & 15.50 & 465.00 & \\
\hline Ties & $0^{\mathrm{c}}$ & & & \\
\hline
\end{tabular}


Berdasarkan tabel 10 hasil analisis data didapatkan nilai rata - rata peningkatan pengetahuan sesudah pemberian aplikasi sebesar 15,50 dan dengan nilai signifikasi $=0,000$ artinya nilai signifikasi $<0,05$, sehingga dapat disimpulkan bahwa ada perbedaan pengetahuan sebelum dan sesudah di berikan aplikasi edukasi tanda bahaya kehamilan berbasis android.

Aplikasi media edukasi tanda bahaya kehamilan berbasis android dikembangkan dengan 7 tahap, yaitu analisis kebutuhan, desain pengembangan media edukasi, pengembangan media edukasi, validasi ahli, uji coba satu-satu, uji coba kelompok kecil, uji coba kelompok besar.

Persentase penilaian aplikasi dengan menggunakan kuisioner Technology Acceptance Model (TAM) untuk menilai tingkat kegunaan aplikasi mendapati variabel perceived ease to use dari jumlah responden 30 dengan 4 pertanyaan yaitu sebesar 4,06, variabel perceived usefulness dari jumlah responden 30 dengan 3 pertanyaan yaitu sebesar 4,1, variabel trust dari jumlah responden 30 dengan 3 pertanyaan yaitu sebesar 4,04, variabel behavior intention to use dari jumlah responden
30 dengan 3 pertanyaan yaitu sebesar 4,05, dan variabel attitude toward using dari jumlah responden 30 dengan 2 pertanyaan yaitu sebesar 4,11.

Pada ke 5 aspek penilai tersebut menunjukkan bahwa semua nilai ratarata berada di atas nilai tengah antara nilai minimum dan maksimum yaitu nilai 4 yang artinya aplikasi diterima sangat baik oleh ibu hamil.

Aplikasi tanda bahaya kehamilan juga meningkatkan pengetahuan dengan rata-rata peningkatan nilai sebesar 15,50 setelah diberikan aplikasi tanda bahaya kehamilan pada ibu hamil. hal ini juga selaras dengan hasil penelitian yang dilakukan oleh Bayati, Dehghan, Bonyadi, \& Bazrafkan tahun 2018 mendapati bahwa nilai pengetahun tentang kesehatan sebelum intervensi 79,22 dan meningkat menjadi 95,49 setelah diberikan intervensi pendidikan dan promosi kesehatan.

Penelitian ini juga menunjukkan perbedaan pengetahuan sebelum dan sesudah di berikan aplikasi edukasi tanda bahaya kehamilan berbasis android selaras dengan hasil penelitian yang dilakukan oleh Roch et al tahun 2018 menyimpulkan bahwa pendidikan pranatal secara online menjadi salah 
satu faktor penunjang pelayanan kesehatan yang lebih baik.

\section{SIMPULAN DAN SARAN}

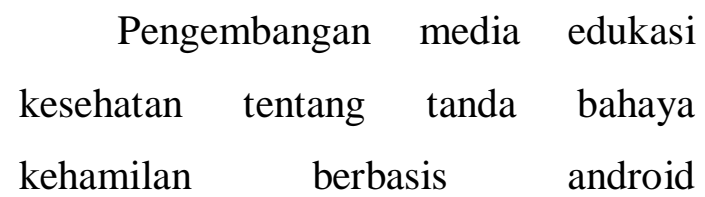
meningkatkan pengetahuan ibu hamil tentang tanda bahaya kehamilan, saran bagi tenaga kesehatan dapat memberikan informasi yang lengkap kepada semua pasien dengan aplikasi sebagai salah satu media perantara pemberian informasi tanda bahaya kehamilan secara cepat dan mudah, sedangkan untuk Ibu Hamil diharapkan mempunyai media untuk mendapatkan informasi secara cepat dan mudah guna mengurangi adanya keterlambatan dalam mengetahui tanda bahaya kehamilan yang harus di tangani secara dini. Saran bagi peneliti lain hendaknya mempunyai ide dan melakukan pengembangan kembali aplikasi media edukasi tanda bahaya kehamilan sehingga bisa menjadi aplikasi pilihan utama dalam penyajian informasi kesehatan pada masa kehamilan

\section{DAFTAR PUSTAKA}

Assaf, S. (2018). Counseling and Knowledge of Danger Signs of Pregnancy. Maternal and Child Health Journal, 22(11), 16591667. https://doi.org/10.1007/s10995018-2563-5.

Bayati, T., Dehghan, A., Bonyadi, F., \& Bazrafkan, L. (2018). Investigating the effect of education on health literacy and its relation to health promoting behaviors in health. Journal of Education and Health Promotion, 7, 1-6. https://doi.org/10.4103/jehp.jehp.

Elliana, D., \& Kurniawati, T. (2015). Perbedaan Pengetahuan dan Persepsi Ibu Hamil Terhadap Penerapan Model SMS Gateway. Jurnal Kesehatan Masyarakat, 10(2), 203-209. https://doi.org/ISSN : 1858-1196

H. R. Borg and M. D. Gall. (1983). Educational Research an Introduction. New York and London: Longman Inc.

Haleema, M., Raghuveer, P., Kiran, R., Mohammed, I. M., Mohammed, I. S. A., \& Mohammed, M. (2019). Assessment of knowledge of obstetric danger signs among pregnant women attending a teaching hospital. Journal of Family Medicine and Primary Care, $8, \quad$ 1422-1426. https://doi.org/10.4103/jfmpc.jfmp c.

Hartini, E. (2018). Asuhan Kebidanan Kehamilan. Malang: Wineka Media. 
Hibstu, D. T., \& Siyoum, Y. D. (2017). Knowledge of obstetric danger signs and associated factors among pregnant women attending antenatal care at health facilities of Yirgacheffe town, Gedeo zone , Southern. BioMed Central, 75, 19. https://doi.org/10.1186/s13690017-0203-y.

Lee, N. M., \& Saha, S. (2013). Nausea and Vomiting of Pregnancy. Gastroenterol Clin North Am, 40(2), 1-27. https://doi.org/10.1016/j.gtc.2011.0 3.009.Nausea.

Mwilike, B., Nalwadda, G., Kagawa, M., Malima, K., Mselle, L., \& Horiuchi, S. (2018). Knowledge of danger signs during pregnancy and subsequent healthcare seeking actions among women in Urban Tanzania : a cross-sectional study. BMC Pregnancy and Childbirth, 18, $1-8$. https://doi.org/10.1186/s12884017-1628-6.

Notoatmodjo S. (2014). Ilmu Perilaku Kesehatan, 2e. Jakarta: Rineka Cipta.
Nursalam, \& Efendi, F. (2014). Pendidikan dalam Keperawatan. Jakarta: Salemba Medika.

Roch, G., Borgès, R., Silva, D., Montigny, F. De, Witteman, H. O., Pierce, T., ... Gagnon, M. (2018). Impacts of online and group perinatal education: a mixed methods study protocol for the optimization of perinatal health services. BMC Health Services Research, 18, 1-8. https://doi.org/10.1186/s12913018-3204-9.

Vallely, L. M., Emori, R., Gouda, H., Phuanukoonnon, S., Homer, C. S. E., \& Vallely, A. J. (2019). Women' s knowledge of maternal danger signs during pregnancy: Findings from a cross-sectional survey in Papua New Guinea. Midwifery, 72, 7-13. https://doi.org/10.1016/j.midw.201 9.02.001.

WHO, UNICEF, \& UNFA. (2015). Trends in Maternal Mortality: 1990 to 2015. (G. Ink, Ed.). Switzerland: WHO. 
Williams, J., Mpembeni, R., Duysburgh, E., Ye, M., Williams, A., Massawe, S., \& Si, A. (2013). Counselling on and women' $\mathrm{s}$ awareness of pregnancy danger signs in selected rural health facilities in Burkina Faso , Ghana and Tanzania. Tropical Medicine and International Health, 18(12), 1498-1509.

https://doi.org/10.1111/tmi.12214 